\title{
Application of Fuzzy Logic in Control of Electrical Machines
}

\author{
Abdel Ghani Aissaoui ${ }^{1}$ and Ahmed Tahour ${ }^{2}$ \\ ${ }^{1}$ Faculty of Science \& Technology, \\ University of Bechar, Bechar, \\ ${ }^{2}$ Faculty of Science \& Technology, \\ University of Mascara, Mascara, \\ Algeria
}

\section{Introduction}

During the past decades, fuzzy logic control (FLC) has been one of the most active and fruitful areas for research in the application of fuzzy set theory. It has has been an active research topic in automation and control theory, since the work of Mamdani proposed in 1974 based on the fuzzy sets theory of Zadeh (1965), to deal with the system control problems which is not easy to be modeled [Mamdani E.H. 1974].

The literature in fuzzy control has been growing rapidly in recent years, making it difficult to present a comprehensive survey of the wide variety of applications that have been made. Fuzzy logic, which is the logic on which fuzzy control is based, is much closer in spirit to human thinking and natural language than the traditional logical systems. Basically, it provides an effective means of capturing the approximate and the inexact nature of the real world. The fuzzy logic controller is a set of linguistic control rules related by the dual concepts of fuzzy implication and the compositional rule of inference. The FLC provides an algorithm which can convert the linguistic control strategy based on expert knowledge into an automatic control strategy.

The concept of FLC is to utilize the qualitative knowledge of a system to design a practical controller. For a process control system, a fuzzy control algorithm embeds the intuition and experience of an operator designer and researcher. The fuzzy control method is suitable for systems with non-specific models, and therefore, it suits well to a process where the model is unknown or ill-defined and particularly to systems with uncertain or complex dynamics [Yu F. M. et al 2003].

The implementation of such control consists of translating the input variables to a language like: positive big, zero, negative small, etc. and to establish control rules so that the decision process can produce the appropriate outputs. Fuzzy control (FC) using linguistic information possesses several advantages such as robustness, model-free, universal approximation theorem and rules-based algorithm [Kim Y.T.\& Bien Z. 2000; Lee C.C. 1990; Timothy J. R. 1994]. 
As an intelligent control technology, fuzzy logic control (FLC) provides a systematic method to incorporate human experience and implement nonlinear algorithms, characterized by a series of linguistic statements, into the controller. In general, a fuzzy control algorithm consists of a set of heuristic decision rules and can be regarded as an adaptive and nonmathematical control algorithm based on a linguistic process, in contrast to a conventional feedback control algorithm [Sousa G.C. D.\& Bose B. K. 1994; Yager, R. R. 1997].

The fuzzy control also works as well for complex nonlinear multi-dimensional system, system with parameter variation problem or where the sensor signals are not precise. It is basically nonlinear and adaptive in nature, giving robust performance under parameter variation and load disturbance effect.

In process control applications, recent literature has explored the potentials of fuzzy control for machine drive application [Tang Y. \& Xu L. 1994, Heber B. et al 1995 ]. It has been shown that a properly designed direct fuzzy controller can outperform conventional proportional integral derivative (PID) controllers [Heber B. et al 1995 ].

This paper presents an application of fuzzy logic to control the speed of a synchronous machine (SM). Based on the analysis of the SM transient response and fuzzy logic, a fuzzy controller is developed. The fuzzy controller generates the variations of the reference current vector of the SM speed control based on the speed error and its change. Digital simulation results shows that the designed fuzzy speed controller realises a good dynamic behaviour of the motor, a perfect speed tracking with no overshoot and a good rejection of impact loads disturbance. The results of applying the fuzzy logic controller to a SM show best performances and high robustness than those obtained by the application of a conventional controller (PI). In this paper, we propose several controllers based on fuzzy logic, to deduce the best one.

The organization of this paper is as follows: in section 2, the fuzzy logic control principle is described and used to design fuzzy logic controllers; in section 3, vector control principle for synchronous motor drive is presented, the proposed controllers are used to control the synchronous motor speed. In section 4, simulation results are given to show the effectiveness of these controllers and finally conclusions are summarized in the last section.

\section{Fuzzy logic control}

The structure of a complete fuzzy control system consists of the following main parts:

- Fuzzification,

- Knowledge base,

- Inference engine,

- Defuzzification.

Figure (1) shows the internal configuration of a fuzzy logic controller.

\subsection{Fuzzy logic principle}

The fuzzification module converts the crisp values of the control inputs into fuzzy values. A fuzzy variable has values which are defined by linguistic variables (fuzzy sets or subsets) such as low, Medium, high, big, slow... where each one is defined by a gradually varying 


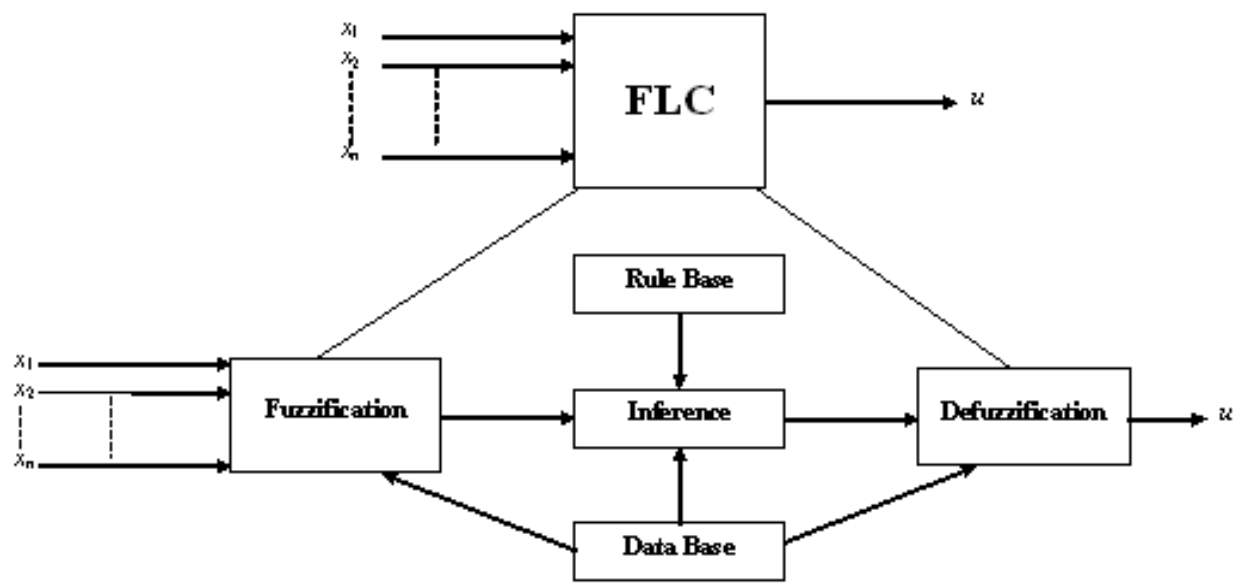

Fig. 1. The internal configuration of a fuzzy logic controller

membership function. In fuzzy set terminology, all the possible values that a variable can assume are named universe of discourse, and the fuzzy sets (characterized by membership functions) cover the whole universe of discourse. The shape of fuzzy sets can be triangular, trapezoïdale, etc [BOSE B. K. 1994; Bühler H. 1994].

A fuzzy control essentially embeds the intuition and experience of a human operator, and sometimes those of a designer and researcher. The data base and the rules form the knowledge base which is used to obtain the inference relation $\mathrm{R}$. The data base contains a description of input and output variables using fuzzy sets. The rule base is essentially the control strategy of the system. It is usually obtained from expert knowledge or heuristics, it contains a collection of fuzzy conditional statements expressed as a set of IF-THEN rules, such as:

$$
\mathrm{R}^{(\mathrm{i})} \text { : If } x_{1} \text { is } \mathrm{F}_{1} \text { and } x_{2} \text { is } \mathrm{F}_{2} \ldots \text { and } x_{n} \text { is } \mathrm{F}_{n} \text { THEN } \mathrm{Y} \text { is } \mathrm{G}(\mathrm{i}), \mathrm{i}=1, \ldots, \mathrm{M}
$$

where : $\left(x_{1}, x_{2}, \ldots, x_{n}\right)$ is the input variables vector, $\mathrm{Y}$ is the control variable, $\mathrm{M}$ is the number of rules, $n$ is the number of fuzzy variables, $\left(\mathrm{F}_{1}, \mathrm{~F}_{2}, \ldots \mathrm{F}_{n}\right)$ are the fuzzy sets.

For the given rule base of a control system, the fuzzy controller determines the rule base to be fired for the specific input signal condition and then computes the effective control action (the output fuzzy variable) [Bose B. K. 1994 ; Spooner J.T. et al 2002].

The composition operation is the method by which such a control output can be generated using the rule base. Several composition methods, such as max-min or sup-min and max-dot have been proposed in the literature.

The mathematical procedure of converting fuzzy values into crisp values is known as 'defuzzification'. A number of defuzzification methods have been suggested. The choice of 
defuzzification methods usually depends on the application and the available processing power. This operation can be performed by several methods of which center of gravity (or centroïd) and height methods are common [Spooner J.T. et al 2002 ; Rachid A. 1996].

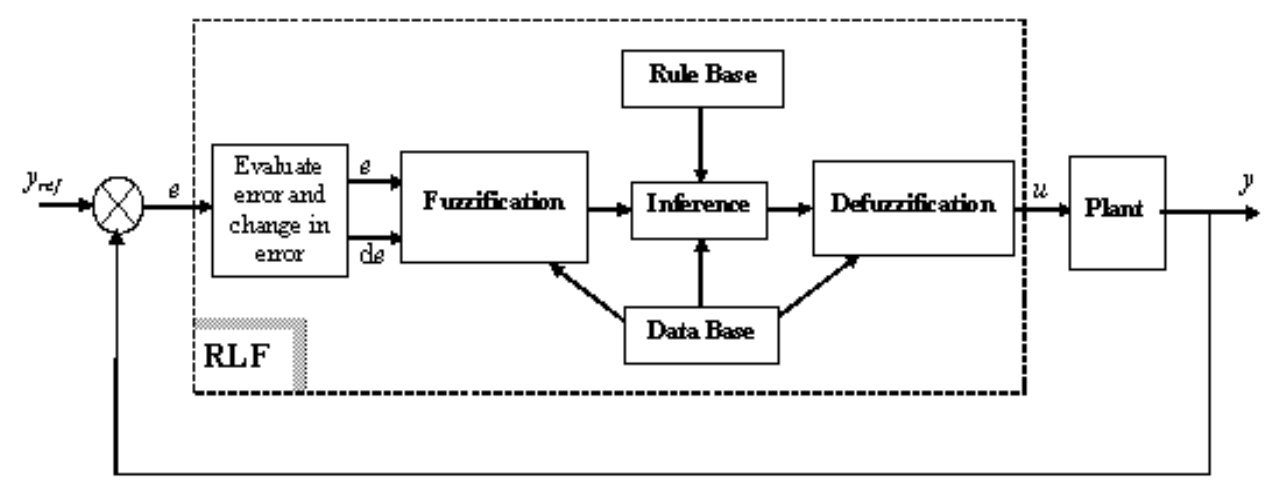

Fig. 2. Basic structure of fuzzy control system

The actual crisp input are approximates to the closer values of the respective universes of discourse. Hence, the fuzzy inputs are described by singleton fuzzy sets.

The elaboration of this controller is based on the phase plan. The control rules are designed to assign a fuzzy set of the control input $u$ for each combination of fuzzy sets of $e$ and $\Delta e$ [Aissaoui A. G. et al 2007]. The performances of such controller depend on the quality of rules and the choice of the fuzzy sets that describe number of the inputs and the output of the controller.

\subsection{Fuzzy control with three fuzzy subsets}

Table 1 shows one of possible control rules based on three membership functions [Aissaoui 2007].

\begin{tabular}{|c|c|c|c|c|}
\hline \multirow{2}{*}{$u$} & \multicolumn{3}{|c|}{$d e$} \\
\cline { 2 - 5 } \multicolumn{2}{|c|}{$u$} & $\mathrm{~N}$ & $\mathrm{Z}$ & $\mathrm{P}$ \\
\hline \multirow{4}{*}{$e$} & $\mathrm{~N}$ & $\mathrm{~N}$ & $\mathrm{~N}$ & $\mathrm{Z}$ \\
\cline { 2 - 5 } & $\mathrm{Z}$ & $\mathrm{N}$ & $\mathrm{Z}$ & $\mathrm{P}$ \\
\cline { 2 - 5 } & $\mathrm{P}$ & $\mathrm{Z}$ & $\mathrm{P}$ & $\mathrm{P}$ \\
\hline
\end{tabular}

Table 1. Rules Base for speed control

The columns represent the rate of the error change $d e$ and the rows represent the error $e$. Each pair $(e, d e)$ determines the output level $\mathrm{N}$ to $\mathrm{P}$ corresponding to $\boldsymbol{u}$.

Here $\mathrm{N}$ is negative, $\mathrm{Z}$ is zero, $\mathrm{P}$ is positive, are labels of fuzzy sets and their corresponding membership functions are depicted in figure (3). Figure (4) shows the corresponding output surface. 

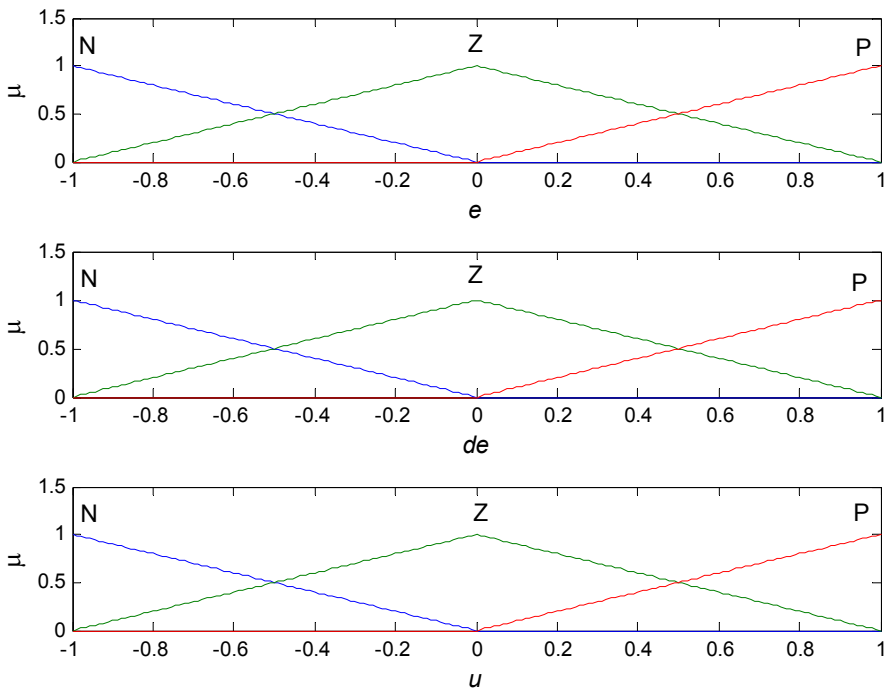

Fig. 3. Membership functions for input e, de and $u$

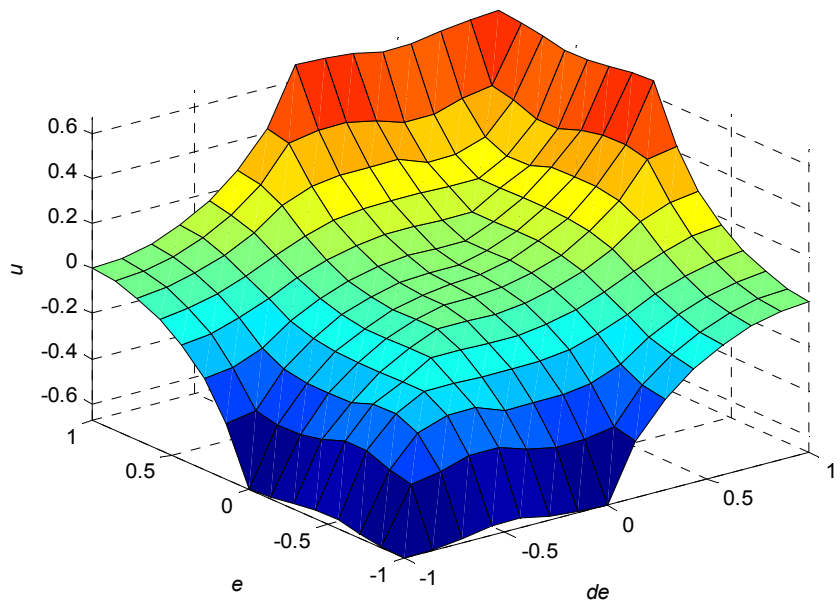

Fig. 4. The output surface of the fuzzy inference system for three fuzzy subsets using the inputs and the output.

\subsection{Fuzzy control with five fuzzy subsets}

Table 1 shows one of possible control rules based on five membership functions [Aissaoui et al 2007]. 


\begin{tabular}{|c|c|c|c|c|c|c|}
\hline \multirow{2}{*}{$u$} & \multicolumn{5}{|c|}{$d e$} \\
\cline { 2 - 7 } & NB & NM & ZR & PM & PB \\
\hline \multirow{4}{*}{$e$} & NB & NB & NB & NM & NM & ZR \\
\hline & NM & NB & NM & NM & ZR & PM \\
\hline & ZR & NM & NM & ZR & PM & PM \\
\cline { 2 - 7 } & PM & NM & ZR & PM & PM & GP \\
\cline { 2 - 7 } & PB & ZR & PM & PM & GP & GP \\
\hline
\end{tabular}

Table 2. Rules Base for speed control

Here NB is negative big, NM is negative medium, $\mathrm{ZR}$ is zero, $\mathrm{PM}$ is positive medium and $\mathrm{PB}$ is positive big, are labels of fuzzy sets and their corresponding membership functions are depicted in figures (5). Figure (6) shows the corresponding output surface.
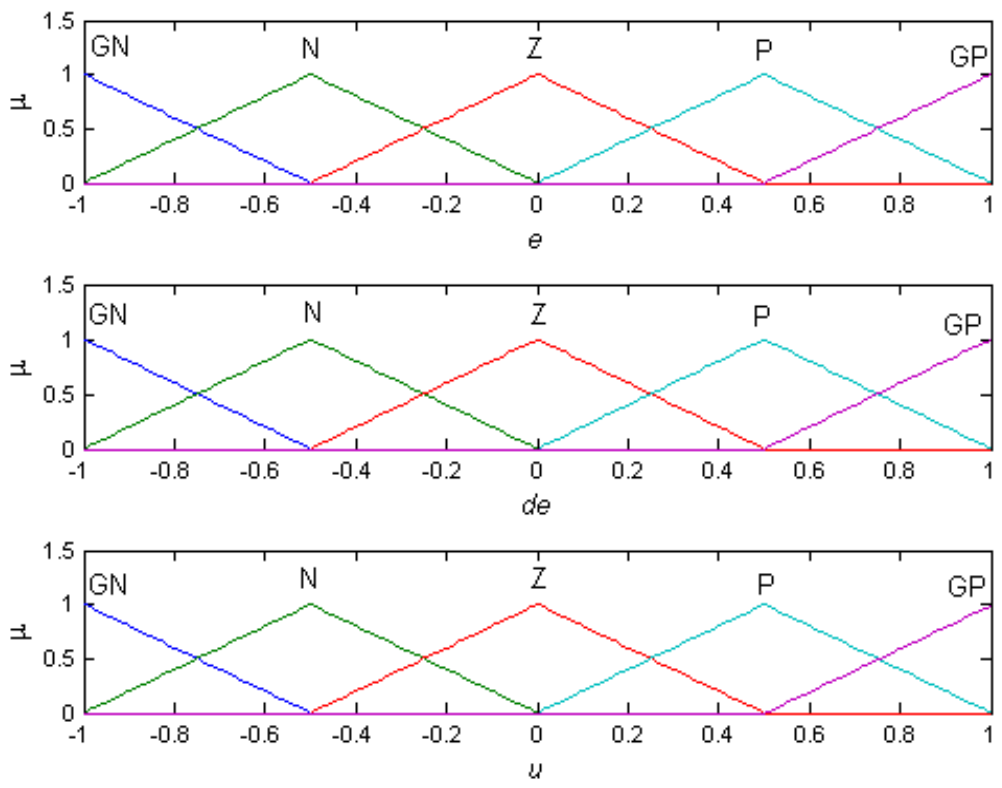

Fig. 5. Membership functions for input e, de and $u$ 


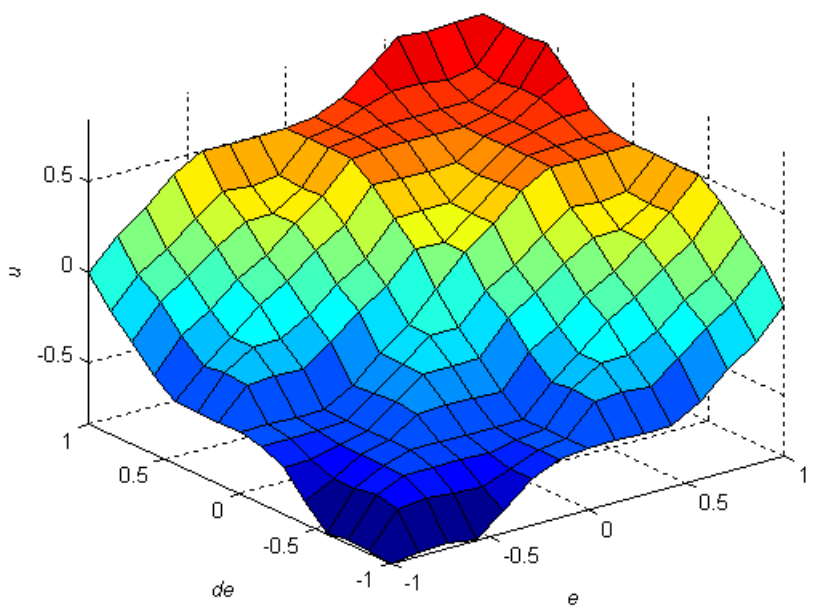

Fig. 6. The output surface of the fuzzy inference system for five fuzzy subsets using the inputs and the output.

\subsection{Fuzzy control with seven fuzzy subsets}

Table 3 shows one of possible control rules based on seven membership functions [Aissaoui et al 2011].

\begin{tabular}{|c|c|c|c|c|c|c|c|c|}
\hline de & $\begin{array}{l}\mathbf{e} \\
\mathbf{u}\end{array}$ & NB & NM & NS & $\mathrm{Z}$ & PS & PM & PB \\
\hline NB & & NB & NB & NB & NB & NM & NS & $\mathrm{Z}$ \\
\hline NN & & NB & NB & NB & NM & NS & $\mathbf{Z}$ & PS \\
\hline NS & & NB & NB & NM & NS & $\mathbf{Z}$ & PS & $\mathbf{P M}$ \\
\hline Z & & NB & NM & NS & Z & PS & PM & PB \\
\hline PS & & NM & NS & $\mathbf{Z}$ & PS & PM & PB & PB \\
\hline PM & & NS & Z & PS & PM & PB & PB & PB \\
\hline PB & & Z & PS & PM & PB & PB & PB & PB \\
\hline
\end{tabular}

Table 3. Rules Base for speed control

Here NS is negative small and PS is positive small. The labels of fuzzy sets and their corresponding membership functions are depicted in figures (7). Figure (8) shows the corresponding output surface. 

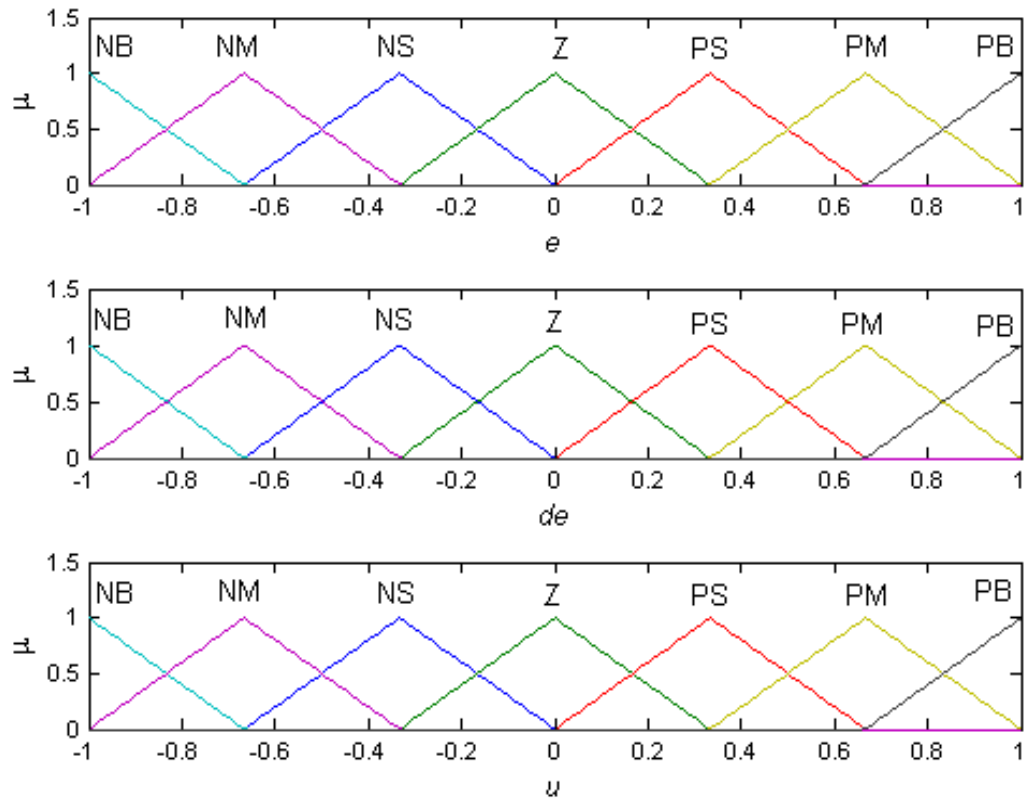

Fig. 7. Membership functions for input e, de and $u$

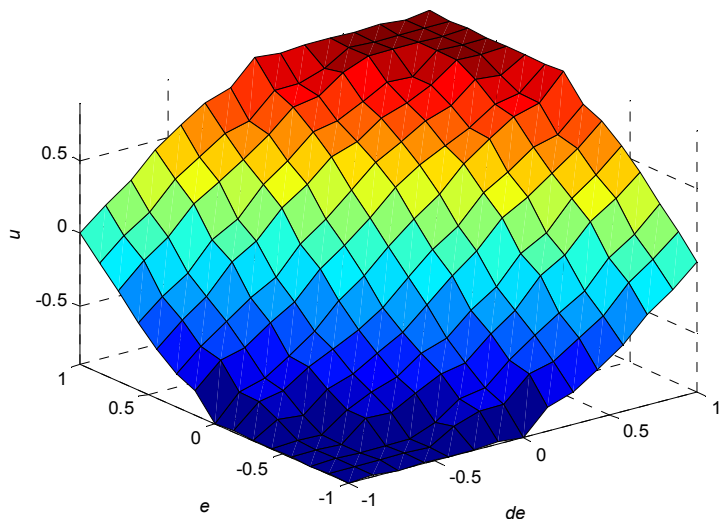

Fig. 8. The output surface of the fuzzy inference system for seven fuzzy subsets using the inputs and the output.

The continuity of input membership functions, reasoning method, and defuzzification method for the continuity of the mapping $u_{f u z z y}(e, \dot{e})$ is necessary. In this paper, the triangular membership function, the max-min reasoning method, and the center of gravity defuzzification method are used, as those methods are most frequently used in many literatures [Bose B. K. 1994; Rachid A. 1996 ]. 


\subsection{Influence of the choice of Membership Function}

The choice of membership functions (MF) is important in the design of fuzzy logic controller. The most MF shapes known and used frequently are: Triangular, Gaussian, Trapezoidal,... Different cases can be subject of our study, following the MF used and their distribution on the universe of discourse.

\subsubsection{Symmetrical Gaussian membership functions}
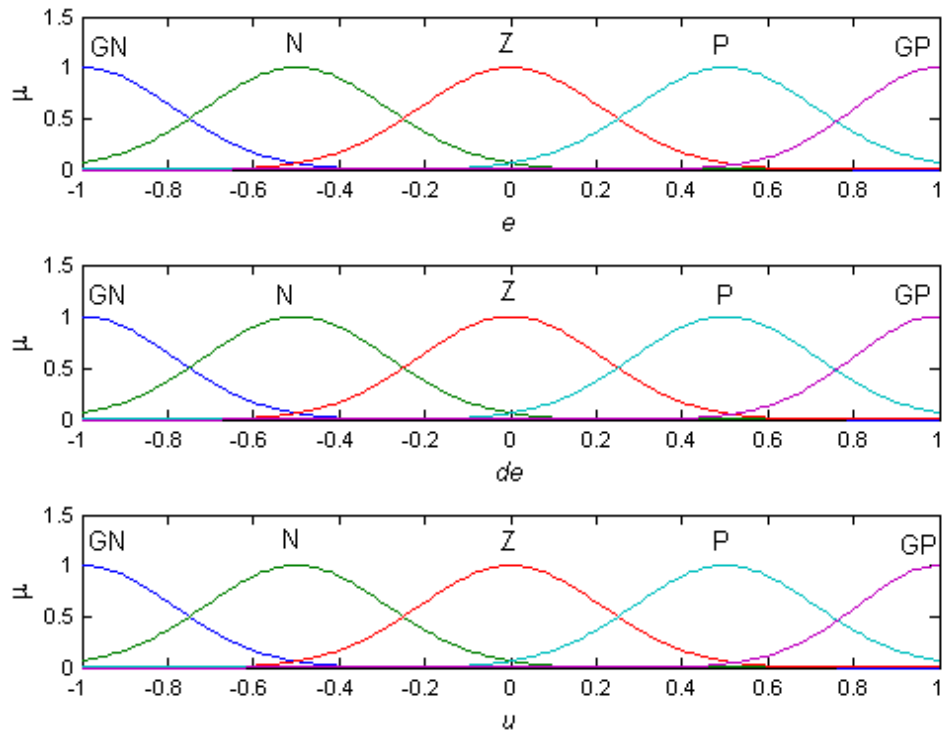

Fig. 9. Membership functions for input e, de and $u$ arranged in symmetrical Gaussian shape.

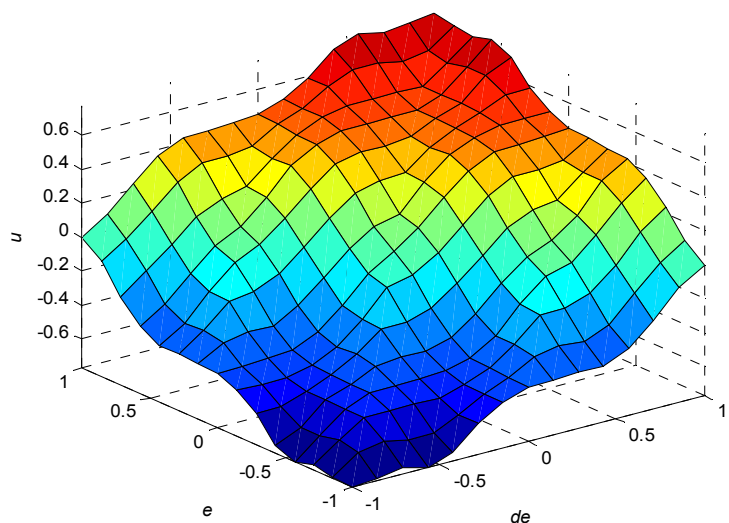

Fig. 10. The output surface of the fuzzy inference system for five fuzzy subsets in symmetrical Gaussian shape. 


\subsubsection{Asymmetrical triangular membership functions}
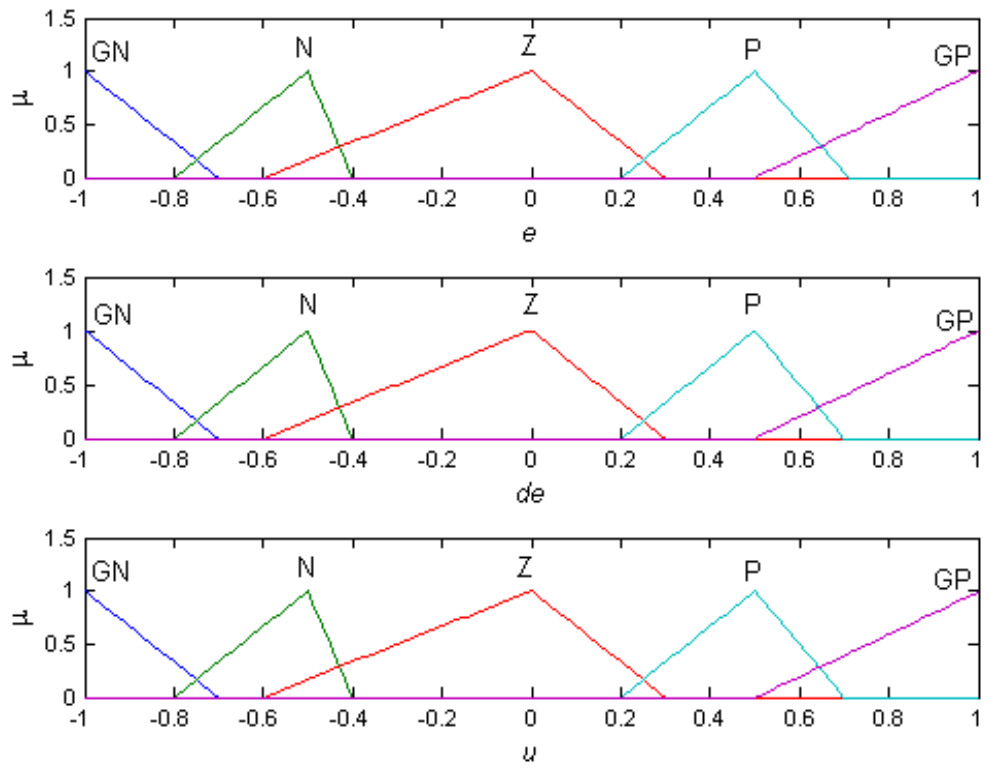

Fig. 11. Membership functions for input e, de et $u$ arranged in asymmetrical shape.

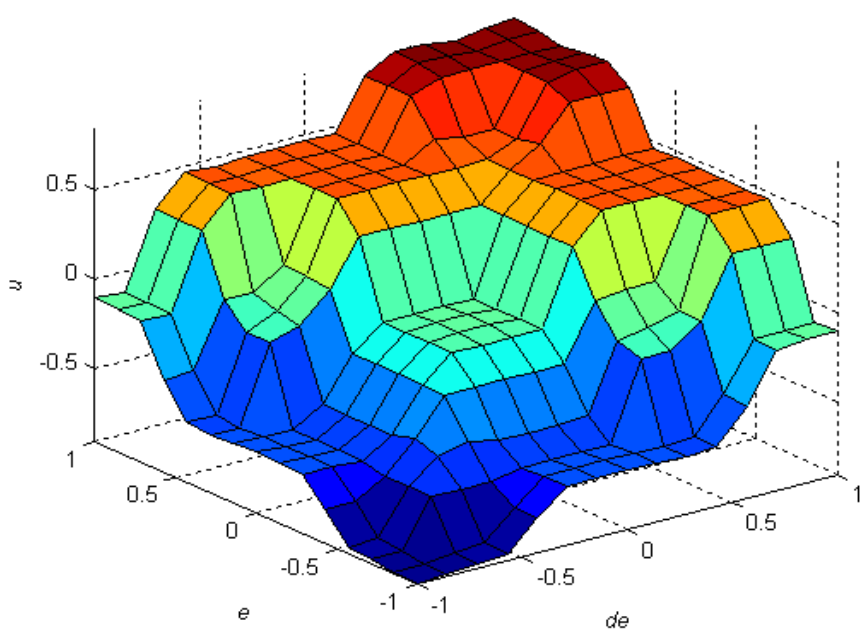

Fig. 12. The output surface of the fuzzy inference system for five fuzzy subsets arranged in asymmetrical shape.. 


\subsubsection{Limit recovery of fuzzy sets}
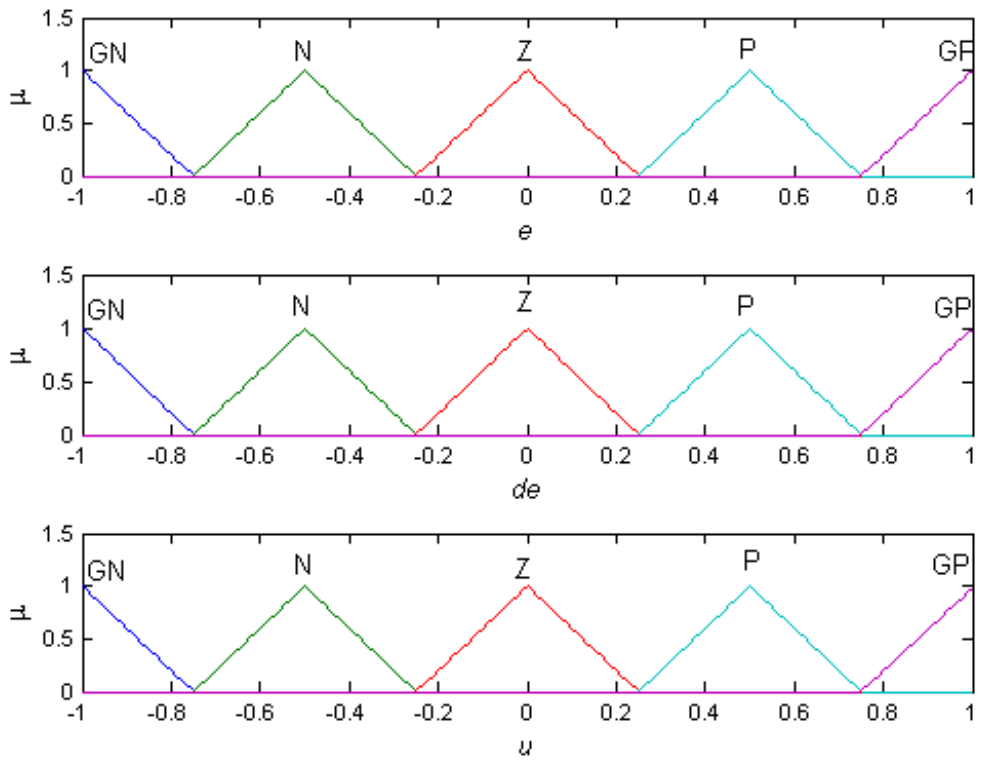

Fig. 13. Membership functions for input $\mathrm{e}, d e$ and $u$ arranged in symmetrical triangular shape and with limit recovery of the fuzzy sets

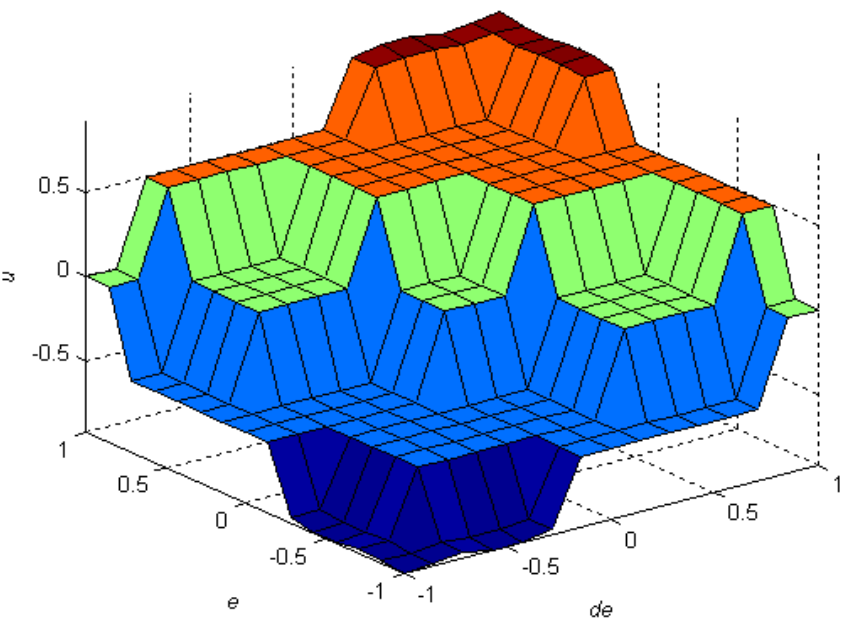

Fig. 14. The output surface of the fuzzy inference system for five fuzzy subsets arranged in symmetrical triangular shape and with limit recovery of the fuzzy sets. 


\subsubsection{Non recovery of of fuzzy sets}
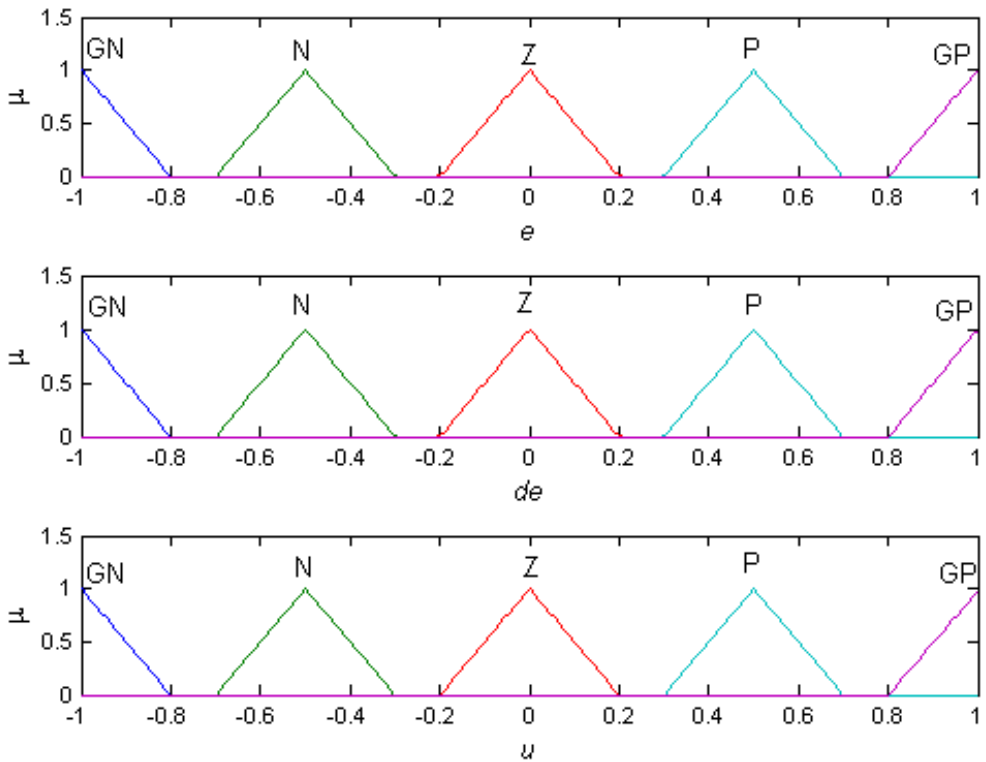

Fig. 15. The output surface of the fuzzy inference system for five fuzzy subsets arranged in symmetrical triangular shape and with non-recovery of the fuzzy sets

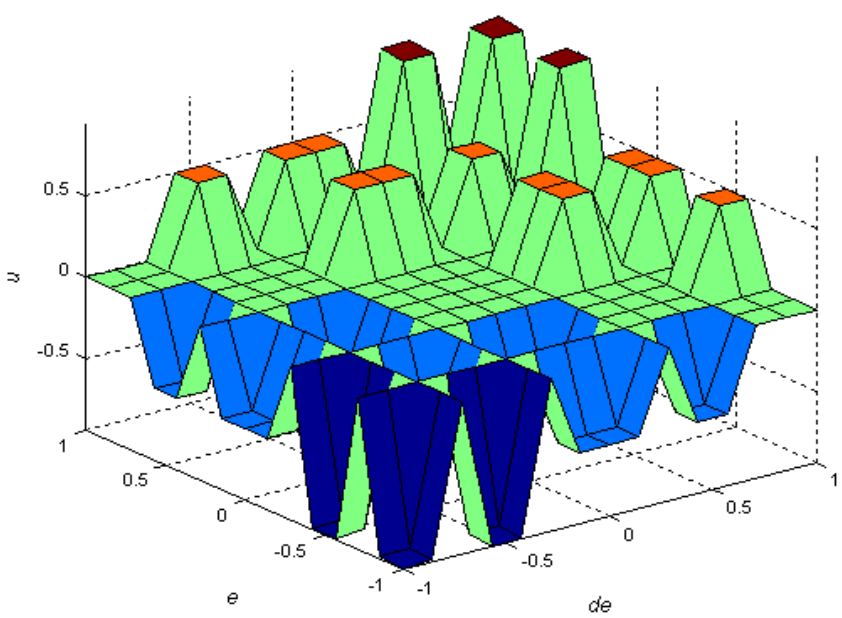

Fig. 16. The output surface of the fuzzy inference system for five fuzzy subsets arranged in symmetrical triangular shape and with non-recovery of the fuzzy sets 


\subsubsection{Interpretation and discussion}

In this section, we have based our study on Triangular MF. It gives same results compared to Gaussian MF as it can see in figures (6) and (10) which represent the output surface of the fuzzy inference system of the inputs ( $e$ and $d e$ ) and the output $(u)$.

The symmetry and the recovery of the fuzzy sets (or MF) are important and they significantly affect the performance of FLC. It appears clearly in the surface of fuzzy inference system (figures $6,12,14,16$ ). It is better to choose the MF with a symmetrical shape and the recovery of two to three fuzzy sets is very interest. This comparison is made using the rules base presented in Table 2.

\section{Description of machine drive}

The schematic diagram of the speed control system under study is shown in figure (17). The power circuit consists of a continuous voltage supply which can provided by a six rectifier thyristors and a three phase GTO thyristors inverter whose output is connected to the stator of the synchronous machine. The field current $i_{f}$ of the synchronous machine, which determines the field flux level is controlled by voltage $v_{f}$ [Aissaoui, A. G. et al 2010; Namuduri, C. \& Sen,P. C. 1987].

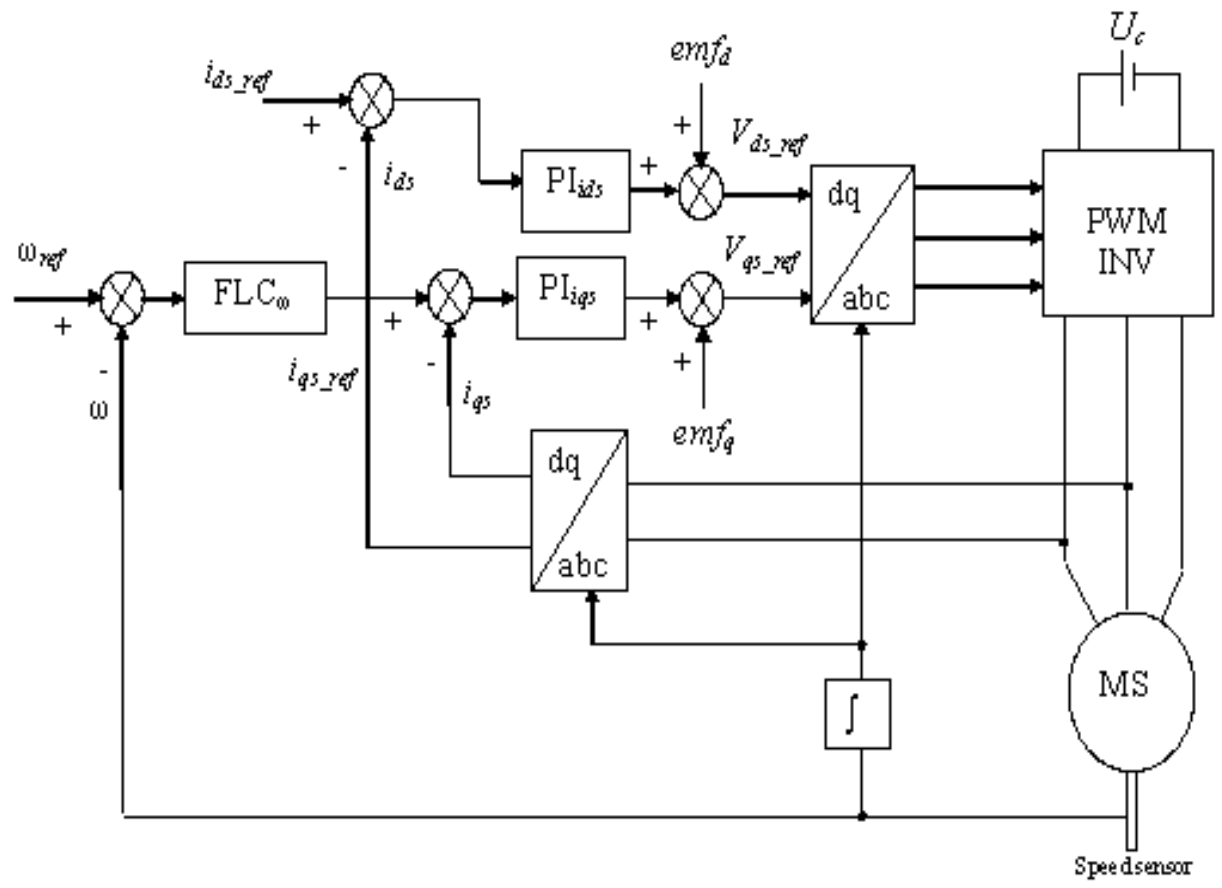

Fig. 17. System Configuration of Field-Oriented Synchronous Motor Control. 
The parameters of the synchronous machine are:

Rated output power $3 \mathrm{HP}$, Rated phase voltage 60V, Rated phase current $14 \mathrm{~A}$, Rated field voltage $v_{f}=1.5 \mathrm{~V}$, Rated field current $i_{f}=30 \mathrm{~A}$, Stator resistance $R_{s}=0.325 \Omega$, Field resistance $R_{f}=0.05 \Omega$, Direct stator inductance $L_{d s}=8.4 \mathrm{mH}$, Quadrature stator inductance $L_{q s}=3.5 \mathrm{mH}$, Field leakage inductance $L_{f}=8.1 \mathrm{mH}$, Mutual inductance between inductor and armature $M_{f d}=7.56 \mathrm{mH}$, The damping coefficient $B=0.005 \mathrm{~N} . \mathrm{m} / \mathrm{s}$, The moment of inertia $J=0.05$ kg.m2, Pair number of poles $p=2$.

Figure (17) shows the schematic diagram of the speed control of synchronous motor using fuzzy logic controller.

\subsection{Machine equations}

The more comprehensive dynamic performance of a synchronous machine can be studied by synchronously rotating $\mathrm{d}$-q frame model known as Park equations. The dynamic model of synchronous motor in $\mathrm{d}-\mathrm{q}$ frame can be represented by the following equations [Sturtzer, G. \& Smigiel E. 2000; Cambronne, J. P. et al 1996]:

$$
\begin{aligned}
& v_{d s}=\mathrm{R}_{\mathrm{s}} i_{d s}+\frac{\mathrm{d}}{\mathrm{d} t} \phi_{d s}-\omega \phi_{q s} \\
& v_{q s}=\mathrm{R}_{\mathrm{s}} i_{q s}+\frac{\mathrm{d}}{\mathrm{d} t} \phi_{q s}+\omega \phi_{d s} \\
& v_{f}=\mathrm{R}_{\mathrm{f}} i_{f}+\frac{\mathrm{d}}{\mathrm{d} t} \phi_{f}
\end{aligned}
$$

The mechanical equation of synchronous motor can be represented as:

$$
\mathrm{J} \frac{\mathrm{d}}{\mathrm{d} t} \Omega=T_{e}-T_{l}-\mathrm{B} \Omega
$$

Where the electromagnetic torque is given in $\mathrm{d}-\mathrm{q}$ frame:

$$
T_{e}=\mathrm{p}\left(\phi_{d s} i_{q s}-\phi_{q s} i_{d s}\right)
$$

In which: $\Omega=\frac{\mathrm{d}}{\mathrm{d} t} \theta, \theta=\int \Omega d t, \omega=\frac{\mathrm{d}}{\mathrm{d} t} \theta_{e}=\mathrm{p} \Omega, \theta_{e}=\mathrm{p} \theta$.

The flux linkage equations are:

$$
\begin{aligned}
& \phi_{d s}=\mathrm{L}_{\mathrm{ds}} i_{d s}+\mathrm{M}_{\mathrm{fd}} i_{f} \\
& \phi_{q s}=\mathrm{L}_{\mathrm{qs}} i_{q s} \\
& \phi_{f}=\mathrm{L}_{\mathrm{f}} i_{f}+\mathrm{M}_{\mathrm{fd}} i_{d s}
\end{aligned}
$$

Where $R_{s}$ - stator resistance, $R_{f}$ - field resistance, $L_{d s}, L_{q s}$ - respectively direct and quadrature stator inductances, $\mathrm{L}_{\mathrm{f}}$ - field leakage inductance, $\mathrm{M}_{\mathrm{fd}}$ - mutual inductance between inductor and armature, $\phi_{d s}$ and $\phi_{q s}$ - respectively direct and quadrature flux, $\phi_{f}$ - 
field flux, $T_{e}$ - electromagnetic torque, $T_{l}$ - external load disturbance, $\mathrm{p}$ - pair number of poles, $\mathrm{B}$ - is the damping coefficient, $\mathrm{J}-$ is the moment of inertia, $\omega$ - electrical angular speed of motor. $\Omega$ - mechanical angular speed of motor, $\theta$ - mechanical rotor position, $\theta_{e}$ -electrical rotor position.

\subsection{Vector control}

The self-control operation of the inverter-fed synchronous machine results in a rotor field oriented control of the torque and flux in the machine. The principle is to maintain the armature flux and the field flux in an orthogonal or decoupled axis. The flux in the machine is controlled independently by the field winding and the torque is affected by the fundamental component of armature current $i_{q s}$. In order to have an optimal functioning, the direct current $i_{d s}$ is maintained equal to zero [Sturtzer G. \& Smigiel E. 2000 ; Cambronne J. P. et al 1996].

Substituting (5) in (4), the electromagnetic torque can be rewritten for $i_{f}=$ constant and $i_{d s}=0$ as follow:

$$
T_{e}(t)=\lambda i_{q s}(t)
$$

where $\lambda=p M_{f d} i_{f}$.

In the same conditions, it appears that the $v_{d s}$ and $v_{q s}$ equations are coupled. We have to introduce a decoupling system, by introducing the compensation terms $e m f_{d}$ and $e m f_{q}$ in which

$$
\begin{aligned}
& e m f_{d}=\omega L_{q s} i_{q s}, \\
& e m f_{q}=-\omega L_{d s} i_{d s}-\omega M_{a f} i_{f} .
\end{aligned}
$$

\section{Simulation results}

In order to validate the control strategies as discussed above, digital simulation studies were made on the system described in figure (17). The speed and currents loops of the drive were also designed and simulated respectively with fuzzy control and PI control. The feedback control algorithms were iterated until best simulation results were obtained.

The speed loop was closed, and transient response was tested with both PI current control and fuzzy speed control. We used several types of fuzzy controller based on the cases presented in section (2.2). The simulation of the starting mode without load is done, followed by reversing the speed reference $\omega_{\text {ref }}= \pm 100 \mathrm{rad} / \mathrm{s}$ at $t_{3}=2 \mathrm{~s}$. The load $\left(T_{l}=7\right.$ N.m $)$ is applied at $t_{1}=1 \mathrm{~s}$ and eliminated at $t_{2}=1.5 \mathrm{~s}$.

The simulation is realized using the SIMULINK software in MATLAB environment.

Figures (18), (19) and (20) show the performances of the fuzzy controller using respectively Table (1), (2) and (3). 

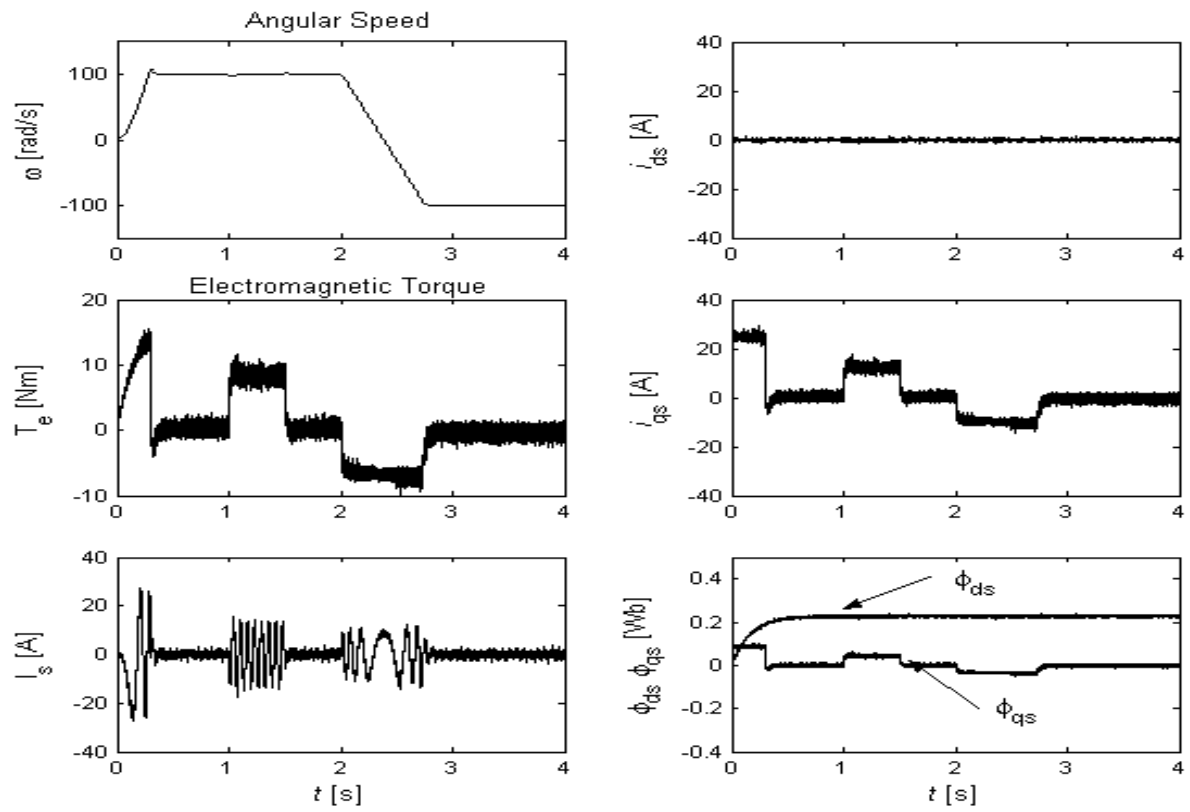

Fig. 18. The response of the system with fuzzy speed controller using Rules base of Table 1 .
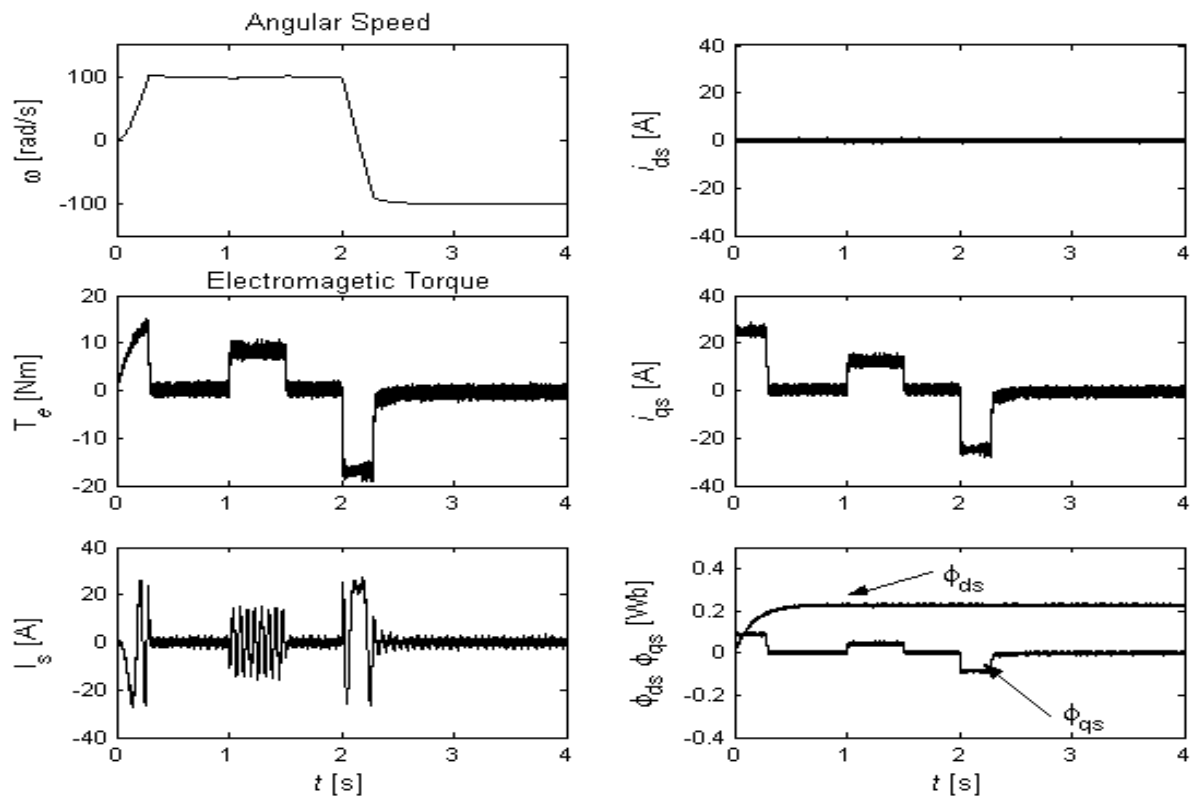

Fig. 19. The response of the system with fuzzy speed controller using Rules base of Table 2 . 

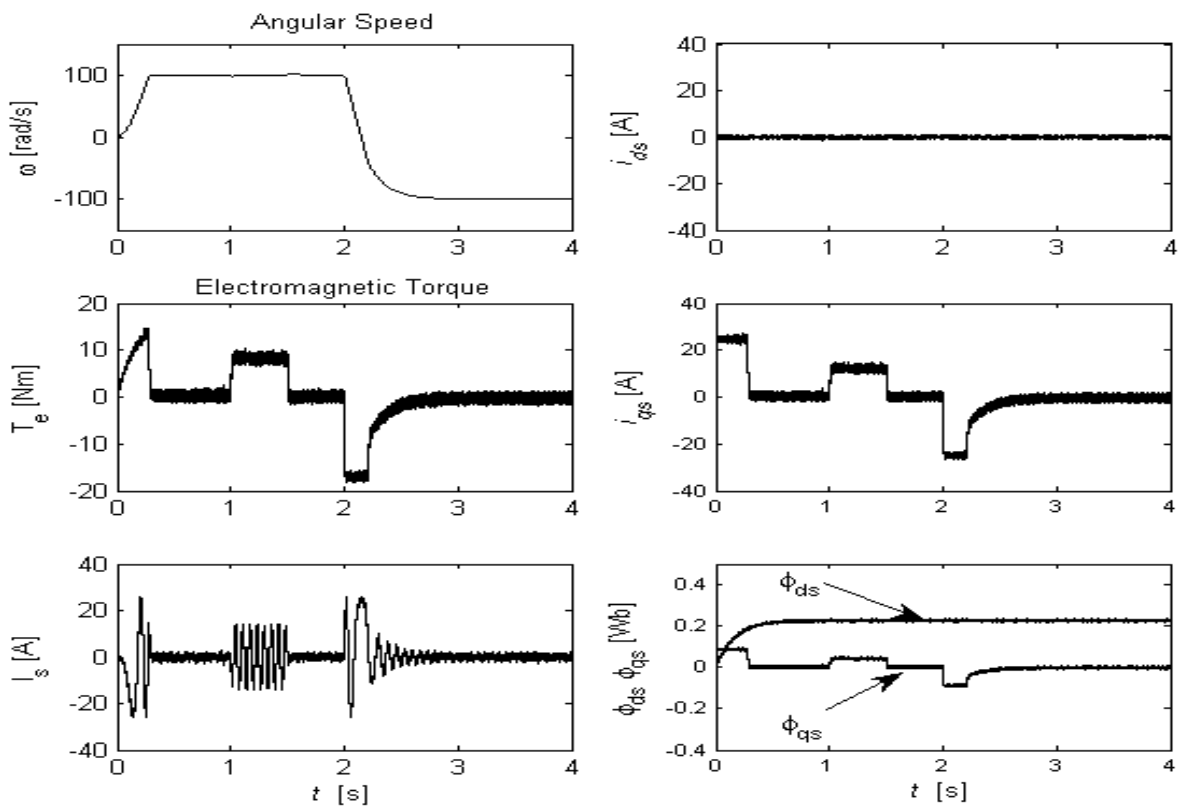

Fig. 20. The response of the system with fuzzy speed controller using Rules base of Table 3.

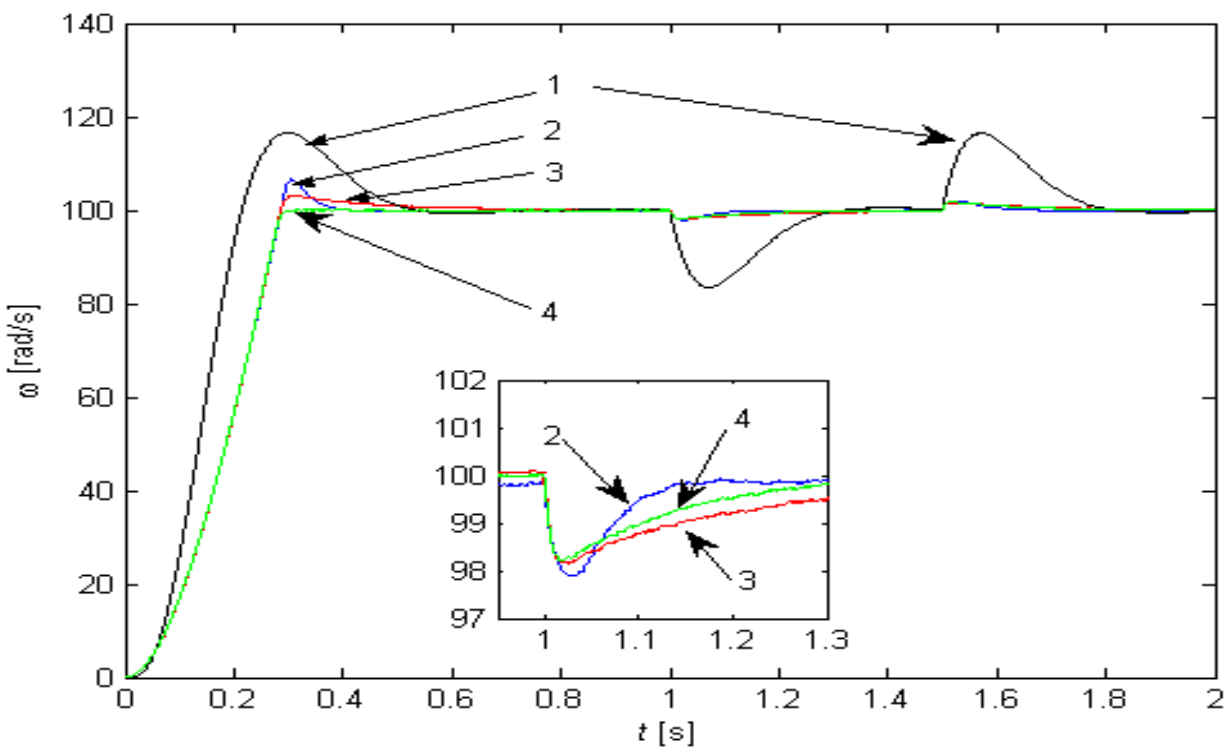

Fig. 21. Comparison of the system response for different controller, 1) PI, 2) 3 Fuzzy subsets 3) 5 Fuzzy subsets, 4) 7 Fuzzy subsets. 
The figures (17-21) show the response of SM with using FLC. The FLC presents high quality to achieve the desired trajectory. It rejects the load disturbances rapidly with no overshoot and with a negligible steady state error. The decoupling of torque-flux is maintained in permanent regime.

The reason of superior performance of fuzzy control system is that it is adaptive in nature and the controller is able to realize different control laws for each inputs state ( $e$ and $d e$ ).

From figure (21), the performances of the FLC can be shown clearly. Compared to PI controller, the FLC give good response to follow the desired trajectory with no overshoot, with a negligible steady state error and with the immediately reject of load disturbances.

The increase of the membership functions in fuzzification and defuzzification improve the quality of the FLC as it is shown in figure (21), however the computation time increase two. It will be better to have a FLC with high performance and with less computation time. The choice of FLC with five Fuzzy-subsets may fulfil these criteria.

Figure (22) shows the influence of the choice of MF on the performance of control.

The choice of MF affects the performances of the FLC, it appears in figure (22) that the triangular or the Gaussian shape doesn't affect the speed control. However, in the presence of asymmetrical distribution the quality of control is bad. The non recovery of fuzzy set gives worst results. It will be better to choose MF with acceptable recovery of fuzzy sets.

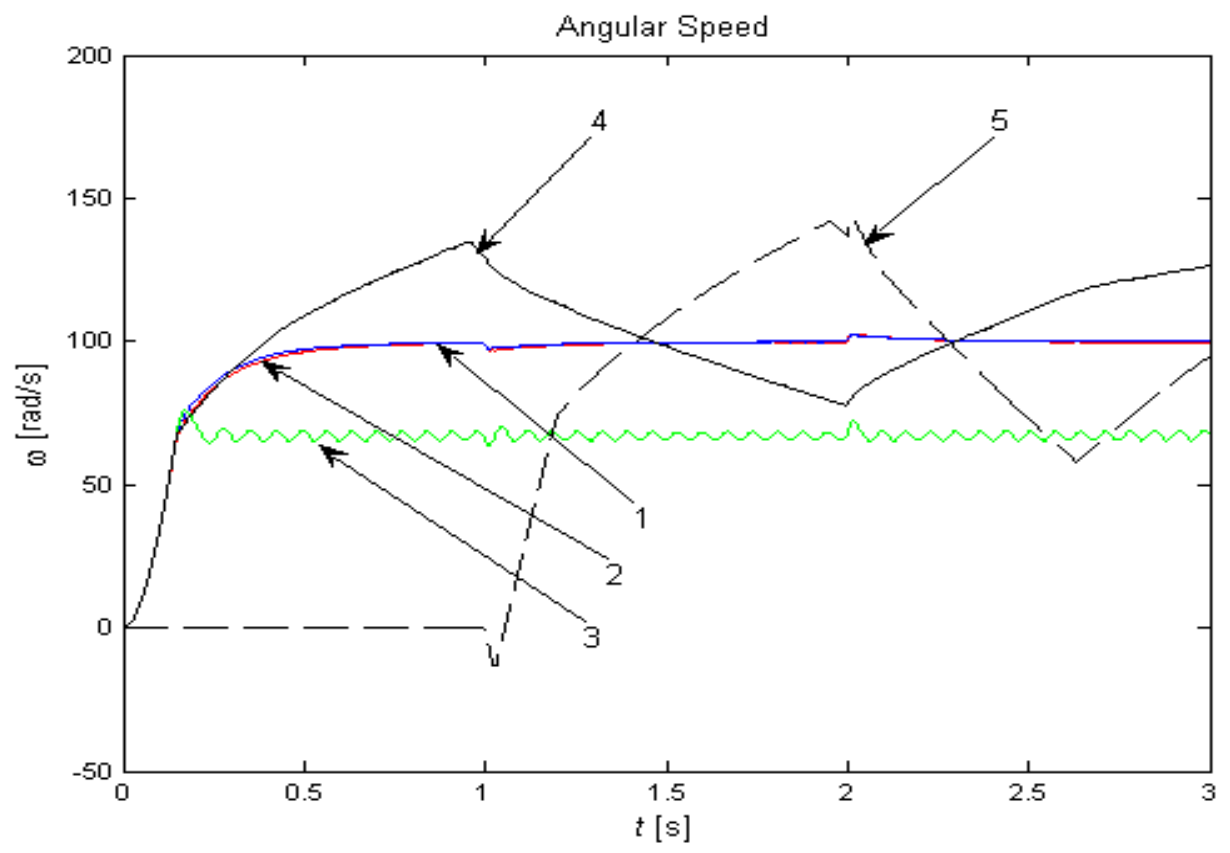

Fig. 22. Comparison of the system response for different MF shape: 1) Triangular, 2)Gaussian, 3) Asymmetrical, 4) limit Recovery, 5) Non recovery. 


\subsection{Robustness}

In order to test the robustness of the used method we have studied the effect of the parameters uncertainties on the performances of the speed control [Aissaoui et al 2007].

To show the effect of the parameters uncertainties, we have simulated the system with different values of the parameter considered and compared to nominal value (real value).

Two cases are considered:

1. The moment of inertia $( \pm 50 \%)$.

2. The stator and rotor resistances $(+50 \%)$.

To illustrate the performances of control, we have simulated the starting mode of the motor without load, and the application of the load $\left(T_{l}=+7 \mathrm{Nm}\right)$ at the instance $t_{1}=2 \mathrm{~s}$ and its elimination at $t_{2}=3 \mathrm{~s}$; in presence of the variation of parameters considered (the moment of inertia, the stator resistances, the stator inductances) with speed step of $+100 \mathrm{rad} / \mathrm{s}$.

Figure (23) shows the tests of robustness realized with the fuzzy controller for different values of the moment of inertia.
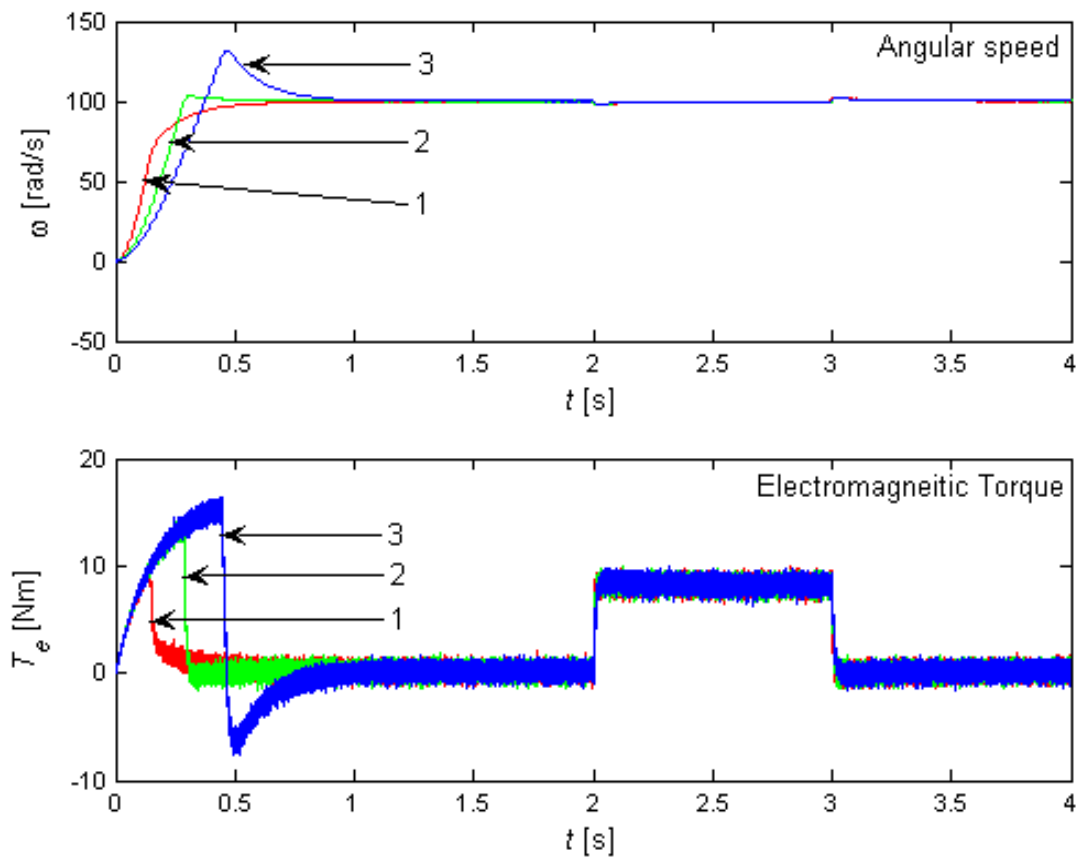

Fig. 23. Test of robustness for different values of the moment of inertia using fuzzy rules of Table 2: 1) - 50\%, 2) nominal case, 3) $+50 \%$.

Figure (24) shows the tests of robustness realized with the fuzzy control for different values of stator and rotor resistances. 

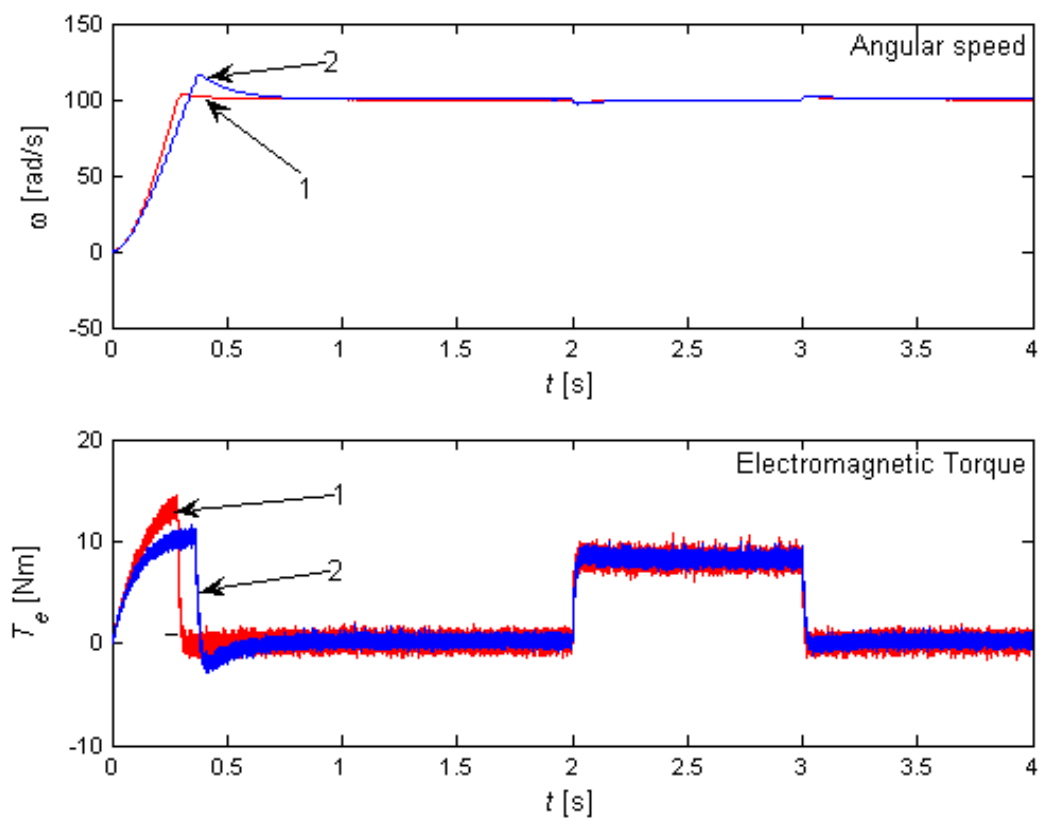

Fig. 24. Test of robustness for different values of stator and rotor resistances using fuzzy rules of Table 2: 1) nominal case, 2 ) $+50 \%$.

For the robustness of control, a decrease or increase of the moment of inertia $J$ or the resistances doesn't have any effects on the performances of the technique used (figures 23 and 24). An increase of the moment of inertia gives best performances, but it presents a slow dynamic response (figure 23). The fuzzy control gives to our controller a great place towards the control of the system with unknown parameters.

\section{Conclusion}

The study describes an application of fuzzy logic system in control of electrical machines. The fuzzy logic control presents a new approach to robust control. The control methodology is described and used to develop a simple robust controller to deal with uncertain parameters and external disturbances. The design of the FLC depends on the structure adopted in fuzzification, defuzzification and rule base. In choice of FLC structure, we have to reach a compromise between the complexity and the precision of controller. The design of the FLC depends on the shape, symmetry and the recovery of MF.

In this study, a complete fuzzy logic control, based on synchronous motor, has been described. The system was analyzed and designed. The performances were studied extensively by simulation to validate the theoretical concept. To avoid the complexity of the FLC and the decrease of its precision, we have adopted five subsets to describe each inputs and output variables. The simulation results show that the proposed controller is superior to conventional controller in robustness and in tracking precision. The simulation study 
indicates clearly the superior performance of FLC, because it is adaptive in nature. It appears from the response properties that it has a high performance in presence of the uncertain plant parameters and load disturbances. It is used to control system with unknown model. The control of speed by FLC gives fast dynamic response with no overshoot and negligible steady-state error. The decoupling, stability and convergence to equilibrium point are verified.

This study will be very helpful, to design a new controllers based on FLC. With use of FLC we can reach high quality in control of non linear systems.

\section{References}

Aissaoui, A. G. 2007. The use of neural networks and fuzzy logic for control of synchronous machine, Phd thesis, University Djilali Liabes of Sidi Bel Abbes, Algeria.

Aissaoui, A. G.; Abid, M.; Abid, H. And Tahour A. \& Zeblah, A.K. (2007). A Fuzzy Logic Controller For Synchronous Machine", Journal of ELECTRICAL ENGINEERING, VOL. 58, NO. 5, 285-290

Aissaoui, A. G.; Abid, M.; Abid, H. And Tahour A.; Megherbi, A. C. (2010). A Fuzzy Logic And Variable Structure Control For Permanent Magnet Synchronous Motors" International Journal Of Systems Control (Ijsc), Vol.1/Iss.1, pp. 13-21.

Aissaoui, A. G.; Abid, M. \& Tahour A. (2010). Application Of Fuzzy Sliding Mode Technique In Controller And Observer Of Synchronous Motor, IEEE International Energy Conference \& Exibition, IEEE-Energycon2010, Manama, Bahrain, December 1822, 2010.

Aissaoui, A. G.; Tahour, A.; Essenbouli, N.; Nollet, F. ; Abid M. \& Chergui, M.I. (2011). A Fuzzy-PI control To Extract An Optimal Power From Wind Turbine, Global Conference on Renewables and Energy Efficiency for Desert Regions and Exibition : GCREEDER 2011, Amman-Jordan, April 26th $-28^{\text {th }} 2011$.

Bose, B. K. (1986). Power electronics and AC drives, Prentice Hall, Englewood Cliffs, Newjersey.

Bose, B. K. (1994). Expert System, Fuzzy logic, and neural network Applications in power Electronics and motion control, Proceedings of the IEEE, Vol. 82, NO. 8, 1303-1321.

Bühler, H. (1994). Réglage par logique floue, Presse Polytechniques et Universitaires romandes, lausanne.

Cambronne, J. P.; Le Moigne Ph. \& Hautier J. P. (1996). Synthèse de la commande d'un onduleur de tension. Journal de Physique III, France, 757-778.

Cirstea, M.N.; Dinu, A.; Khor, J.G.; McCormick, M. (2002). Neural and Fuzzy Logic Control of Drives and Power Systems, Newnes, Oxford.

Heber, B.; Xu, L. \& Tang, Y. (1995). Fuzzy logic enhanced speed control of an indirect field oriented induction machine drive, IEEE PESC Meet., pp. 1288-1294.

Kim, Y.T.; Bien, Z. (2000). Robust self-learning fuzzy controller design for a class of nonlinear MIMO system, Fuzzy Sets and systems 111, 117-135.

Lee, C.C. (1990). Fuzzy logic in control system: fuzzy logic controller-Part I/II, IEEE Trans. systems Man. Cybernet 20, 404-435.

Mamdani E.H. (1974). Applications of fuzzy algorithms for simple dynamic plants, Proc. IEE $121,1585-1588$. 
Namuduri, C. \& Sen,P. C. (1987). A servo-control system using a self-controlled synchronous motor (SCSM) with sliding mode control. IEEE Trans. on Industry Application, vol. IA-23, N².

Rachid, A. (1996). Systèmes de régulation, Masson, paris.

Sousa, G.C. D.; Bose, B. K. (1994). Fuzzy set theory based control of a phase-controlled converter DC machine drive, IEEE Transaction on Industry Applications, Vol. 30, NO. $1,34-44$.

Spooner, J.T.; Maggiore, M.; Ordonez, R; Passino, K. M. (2002). Stable adaptative control and estimation for nonlinear system, Neural and fuzzy approximator techniques, WilleyInterscience.

Sturtzer, G. \& Smigiel E. (2000). Modélisation et commande des moteurs triphasés. Edition Ellipses.

Tang, Y. \& Xu, L. (1994). Fuzzy logic application for intelligent control of a variable speed drive, IEEE PES Winter Meet.

Timothy, J. R. (1994). Fuzzy logic with engineering application, McGraw-Hill, New York, 1995.

Yager, R. R. (1997). Fuzzy logics and artificial intelligence. Fuzzy Sets and Systems 90, 193-198.

Yu, F. M.; Chung, H. Y.; Chen, S. Y..(2003). Fuzzy sliding mode controller design for uncertain time-delayed systems with nonlinear input. Fuzzy Sets Syst., vol. 140, 359-374. 


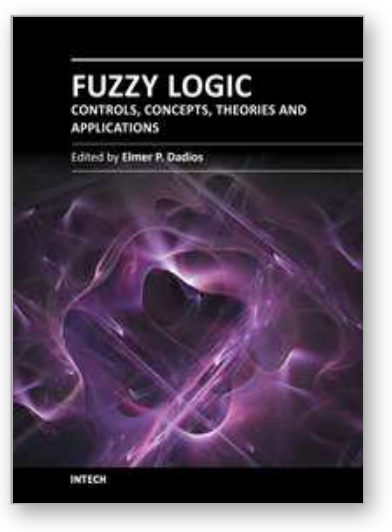

\author{
Fuzzy Logic - Controls, Concepts, Theories and Applications \\ Edited by Prof. Elmer Dadios
}

ISBN 978-953-51-0396-7

Hard cover, 428 pages

Publisher InTech

Published online 28, March, 2012

Published in print edition March, 2012

This book introduces new concepts and theories of Fuzzy Logic Control for the application and development of robotics and intelligent machines. The book consists of nineteen chapters categorized into 1) Robotics and Electrical Machines 2) Intelligent Control Systems with various applications, and 3) New Fuzzy Logic Concepts and Theories. The intended readers of this book are engineers, researchers, and graduate students interested in fuzzy logic control systems.

\title{
How to reference
}

In order to correctly reference this scholarly work, feel free to copy and paste the following:

Abdel Ghani Aissaoui and Ahmed Tahour (2012). Application of Fuzzy Logic in Control of Electrical Machines, Fuzzy Logic - Controls, Concepts, Theories and Applications, Prof. Elmer Dadios (Ed.), ISBN: 978-953-510396-7, InTech, Available from: http://www.intechopen.com/books/fuzzy-logic-controls-concepts-theories-andapplications/-application-of-fuzzy-logic-in-control-of-electrical-machines

\section{INTECH}

open science | open minds

\section{InTech Europe}

University Campus STeP Ri

Slavka Krautzeka 83/A

51000 Rijeka, Croatia

Phone: +385 (51) 770447

Fax: +385 (51) 686166

www.intechopen.com

\section{InTech China}

Unit 405, Office Block, Hotel Equatorial Shanghai

No.65, Yan An Road (West), Shanghai, 200040, China

中国上海市延安西路65号上海国际贵都大饭店办公楼 405 单元

Phone: +86-21-62489820

Fax: +86-21-62489821 
(C) 2012 The Author(s). Licensee IntechOpen. This is an open access article distributed under the terms of the Creative Commons Attribution 3.0 License, which permits unrestricted use, distribution, and reproduction in any medium, provided the original work is properly cited. 